\title{
Propionibacterium acnes infection induces upregulation of inflammatory genes and cytokine secretion in prostate epithelial cells
}

\author{
Johanna B Drott1,2, Oleg Alexeyev1, Patrik Bergström1', Fredrik Elgh'1,2 and Jan Olsson*1,2
}

\begin{abstract}
Background: The immune stimulating bacterium Propionibacterium acnes is a frequent colonizer of benign and malignant prostate tissue. To understand the pathogenesis of the earliest phase of this infection, we examined the $P$. acnes triggered immune response in cultivated prostate epithelial cells.

Results: Prostate epithelial cells are triggered to secrete IL-6, IL-8 and GM-CSF when infected with P. acnes. The secretion of cytokines is accompanied by NFKB related upregulation of the secreted cytokines as well as several components of the TLR2-NFKB signaling pathway.

Conclusions: P. acnes has potential to trigger a strong immune reaction in the prostate glandular epithelium. Upon infection of prostate via the retrograde urethral route, the induced inflammatory reaction might facilitate bacterial colonization deeper in the prostate tissue where persistent inflammation may impact the development of prostate diseases as hyperplasia and/or malignancy.
\end{abstract}

\section{Background}

Asymptomatic histological inflammation is a common feature when prostate tissue is subjected to morphological examination. Varying degree of inflammation is present at both benign (prostatic hyperplasia) and malignant (neoplasia) conditions. A growing amount of research supports the idea that chronic prostatic inflammation contributes to gradual transition of normal epithelial cells to malignant cells [1]. For example, many of the genevariants linked to familiar prostate cancer code for proinflammatory cytokines and chemokines [2]. A plethora of microorganisms have been evaluated for their possible involvement in the etiology of prostate inflammation. Many studies purported E. coli and sexually transmitted agents as likely candidates capable of inducing chronic prostatic inflammation [3-5]. A Gram-positive bacterium; Propionibacterium acnes (P. acnes) has been reported to be frequently present in various prostatic diseases (as reviewed in [6]) and its presence has been correlated to inflammation in prostate cancer specimens [7-9].

* Correspondence: jan.olsson@medbio.umu.se

1 Department of Clinical Microbiology/Virology, Umeå University, SE-901 87 Umeå, Sweden

Full list of author information is available at the end of the article
P. acnes, a well studied pathogenetic factor in cutaneous disorders like acne vulgaris, has been demonstrated to stimulate monocytes and endothelial cells to secrete proinflammatory cytokines via activation of Toll-like receptor (TLR) $2[10,11]$. In this study we present an in vitro model to study the inflammatory response of prostate derived epithelial cells to $P$. acnes infection. We report that $P$. acnes induces upregulation of numerous proinflammatory substances at the mRNA level accompanied by secretion of respective soluble substances such as interleukins 6, 8 and GM-CSF. Components of the TLR2$\mathrm{NF} \kappa \mathrm{B}$ signaling pathway were upregulated, suggesting an involvement of this particular pathway for the response. Blocking of the TLR2 with monoclonal antibodies partly reduced the effects.

\section{Results}

Pilot studies to define experimental conditions for P. acnes infection of epithelial cells

Secretion of cytokines is one of the end results of innate immune response at a cellular level. We therefore assessed the secretion of three key cytokines, IL-6, IL-8 and GM-CSF (also called CSF-2) from the prostatederived epithelial cell-line RWPE-1 in response to infec- 
tion with $P$. acnes. To set experimental conditions as multiplicity of infection (MOI) and useful infection time, we defined the desired criteria as maximal cytokine secretion after $48 \mathrm{~h}$ and no visual cellular detachment or celldeath. A MOI of 16-40:1 fulfilled these criteria (data not shown). We therefore decided to use a MOI of 16:1 for the following experiments.

\section{Prostate epithelial cells secrete IL-6, IL-8, and GM-CSF in response to Propionibacterium acnes infection}

Secretion of cytokines IL-6, IL-8 and GM-CSF by RWPE1 was measured $24 \mathrm{~h}$ and $48 \mathrm{~h}$ after infection with $P$. acnes. $24 \mathrm{~h}$ after infection, the levels of secreted IL-6, IL-8 and GM-CSF were: $441.7 \pm 67.6,3071.1 \pm 133.7$, and 48.6 $\pm 3.1(\mathrm{pg} / \mathrm{ml})$, respectively. The corresponding values from the uninfected control cells were: $17.0 \pm 8.0(\mathrm{pg} / \mathrm{ml})$, not detectable, not detectable (Figure 1). $48 \mathrm{~h}$ after infection, the concentrations increased to: $567.7 \pm 70.7,5121.5$ \pm 218.0 , and $118.6 \pm 10.6(\mathrm{pg} / \mathrm{ml})$. Uninfected: $19.9 \pm 5.8$, $320.6 \pm 71.4$, and $2.1 \pm 0.5(\mathrm{pg} / \mathrm{ml})$. The diagram shows means for triplicates with the error bars representing the standard deviation [12] (Figure 1).

\section{P. acnes induced secretion of IL-8 is partially blocked by a- TLR-2 antibodies}

To determine whether the secretion of IL-6, IL-8, and GM-CSF was TLR2-mediated, TLR2 on RWPE-1 cells were blocked with monoclonal anti-TLR2 antibodies at a concentration of $100 \mathrm{ng} / \mathrm{ml}$ prior to infection. This particular mab clone has previously been demonstrated to block TLR2 activation in human cells [13]. Secretion of IL-8 was significantly $(p=0.05)$ reduced when measured $24 \mathrm{~h}$ after infection (Figure 2). No such blocking effect was recognizable $48 \mathrm{~h}$ after infection. Levels of IL-6 and GM-CSF were not significantly affected (Figure 2). Figure 2 shows means for triplicates with the error bars representing the standard deviation.

\section{P. acnes infection induces up-regulation of several} cytokines and components of the TLR-2 signaling pathway The potent $P$. acnes stimulated effect on secretion of IL-6, IL-8 and GM-CSF prompted us to investigate an array of genes involved in inflammatory signaling pathways. As our main focus is the early responses, we wanted to collect mRNA as early as possible, yet late enough to allow observation of significant regulatory events. We used the cDNA prepared from cells infected for $24 \mathrm{~h}$ for comparison with cDNA from uninfected cells. Of the 84 genes analyzed, 20 were more than two-fold upregulated $(p=$ 0.05): CCL2, CSF2 (GM-CSF), CSF3, CXCL10, IFNB1, IL1A, IL6, IL8, IRAK2, IRF1, JUN, LTA, NFKB2, NFKBIA, REL, RELA, RIPK2, TLR2, TNF, and TICAM1 (Table 1$)$. Only four genes were downregulated $(p=0.05)$ : FOS, HMGB1, TLR4 and UBE2V1 (Table 2).
A

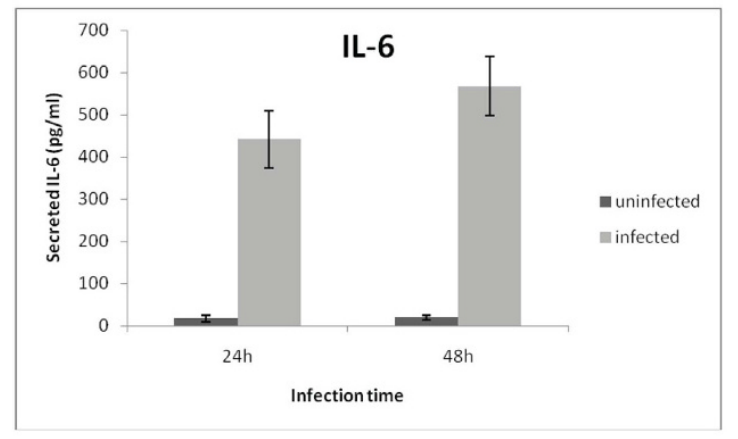

B

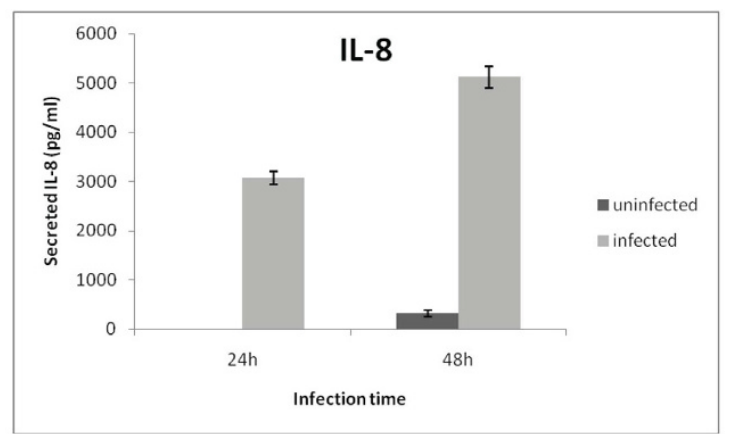

C

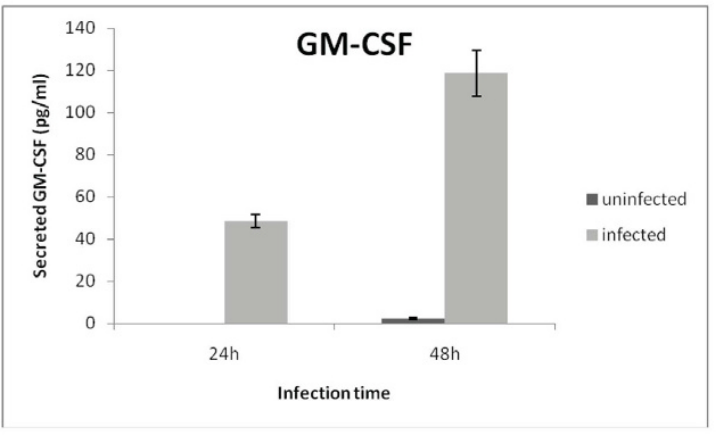

Figure 1 P. acnes-induced secretion of IL-6 (a), IL-8 (b) and GMCSF (c) by RWPE- 1 cells at $24 \mathrm{~h}$ and $48 \mathrm{~h}$ after infection. Semiconfluent RWPE-1 monocell-layers were infected with $P$. acnes at a MOI of 16:1. Cytokines released into supernatants were quantified by ELISA. The diagram shows means for triplicates with the error bars representing the standard deviation.

\section{Discussion}

Prostate specimens commonly display signs of chronic histological inflammation, along with occasional acute inflammation. Numerous studies have explored a possible link between prostate inflammation and cancer development and recent reviews of epidemiologic, genetic, and molecular studies have collectively suggested that the two cellular processes may indeed interact [2,14-16]. Exposure to environmental factors such as infectious agents 
A

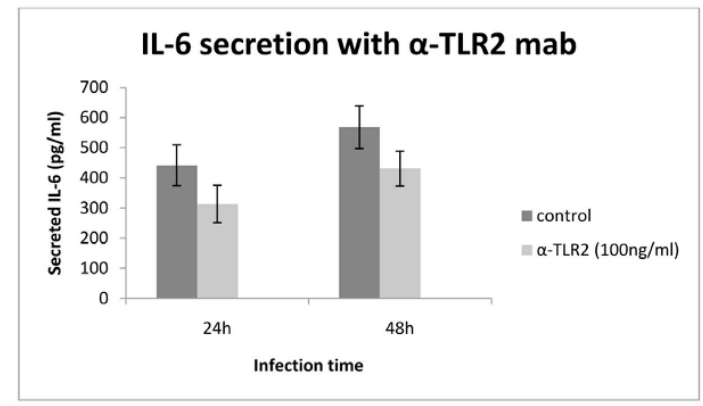

B

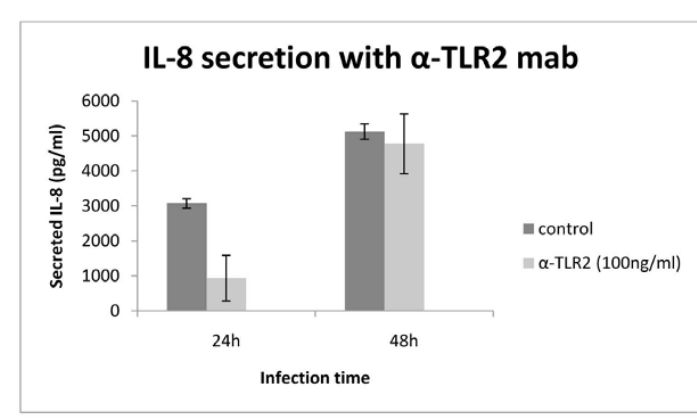

C

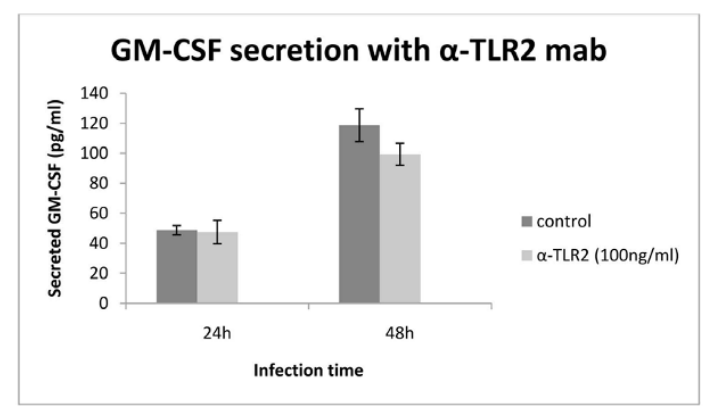

Figure $2 a-T L R 2$ inhibition of IL6, IL-8 and GM-CSF secretion by $P$. acnes-infected RWPE-1. a-TLR2 mouse monoclonal antibodies (100 $\mathrm{ng} / \mathrm{ml}$ ) were added one hour prior to $P$. acnes infection of semiconfluent RWPE-1 monocell-layers. Supernatants were collected at $24 \mathrm{~h}$ and $48 \mathrm{~h}$ after infection. The amount of cytokines released into the medium was quantified by ELISA. The diagram shows means for triplicates with the error bars representing the standard deviation.

can lead to injury of the prostate and to the development of chronic inflammation [17]. The intrinsic interplay between microbes and urogenital cells is a key feature in the understanding of the microbial involvement in prostate disease. Both Chlamydia and Mycoplasma have been demonstrated to induce IL- 6 and IL- 8 production in immortalized normal prostate epithelial cells (PNT2) $[18,19]$. Given the emergence of $P$. acnes as an infecting agent in prostate tissue [7-9] we investigated the effect of the bacterium on prostate epithelial cells of non-malig- nant origin (RWPE-1). In vitro, $P$. acnes induced considerable secretion of IL- 6 and IL- 8 and, to a lesser extent, GM-CSF. Secretion of IL8 was shown to be mediated via TLR2, as the receptor blockage with anti-TLR2 monoclonal antibodies reduced its secretion. In contrast, we did not observe any significant reduction in secretion of IL-6 and GM-CSF by blockage of TLR2. Earlier reports present evidence that $P$. acnes is able to stimulate monocytes and endothelial cells to secrete pro-inflammatory cytokines via activation of TLR2 [10,11]. Our results partly confirm this. Even toll-like receptors 4 and 9 have been implicated in $P$. acnes mediated immune modulatory effects [20]. Both human and rat prostate epithelial cell lines are known to express TLR2, TLR4, and TLR9 $[21,22]$ and since blockage of TLR2 in our experiment has not totally inhibited cytokine secretion, the involvement of other TLR may also be hypothesized. However, possible TLR4 involvement is compromised by the observed downregulation of the gene expression. Another mechanism may involve auto inducing capability of the released cytokines that generates a self-perpetuating inflammatory process.

The increased secretion of such cytokines was accompanied by concordant mRNA up-regulation. Moreover, the broader analysis of inflammation associated genes revealed that chemokine ligands and pro-inflammatory substances CCL2, CXCL10, TNF- $\alpha$, TNF- $\beta$ (lymphotoxin- $\alpha$ ), CSF3, IL1- $\alpha$, and IFN- $\beta$ were also significantly upregulated. Further studies are required to determine if upregulation of aforementioned genes is accompanied by enhanced cytokine production by prostate epithelial cells. The upregulation of the transcriptional regulators JUN, REL, RIPK2, NFKB2, NFKBIA, IRF1, IRAK2 and the TLR/IL1-receptor co-factor TICAM1 is coherent with earlier studies of TLR2 signaling cascade leading to Fib activation $[23,24]$.

Secretion of IL-6, IL-8 and GM-CSF are central for recruitment and differentiation of macrophages and neutrophils in inflamed tissue [25-27]. A prolonged time of increased cytokine levels might have adverse effects on the tissue. P. acnes induced elevation of IL- 8 expression in hair-follicle endothelial cells is associated with epidermal hyperplasia and follicular hyperkeratosis in acne vulgaris and psoriasis $[28,29]$. There is also a correlation between the more pronounced IL-8 expression and dermal angiogenesis [29]. Interestingly, both IL-6 and IL- 8 have been suggested as contributors to prostate cancer development. The expression of IL- 6 and its receptor has been demonstrated in clinical specimens of both prostate cancer and benign prostate hyperplasia [30], and levels of IL6 increase in organ-confined tumors [31]. In vitro experiments have shown that IL-6 may play a role in prostate cancer cell growth and differentiation and that it stimulates cell growth of malignant cells [32]. Following pro- 
Table 1: List of genes that are upregulated upon P. acnes infection.

\begin{tabular}{|c|c|c|}
\hline Gene name & Description & Fold upregulation \\
\hline $\mathrm{CCL} 2$ & Chemokine (C-C motif) ligand 2 & 41 \\
\hline CSF2 & Colony stimulating factor 2 (granulocyte-macrophage) & 139 \\
\hline CSF3 & Colony stimulating factor 3 (granulocyte) & 39 \\
\hline CXCL10 & Chemokine (C-X-C motif) ligand 10 & 107 \\
\hline IFNB1 & Interferon, beta 1, fibroblast & 12 \\
\hline IL1A & Interleukin 1, alpha & 12 \\
\hline IL6 & Interleukin 6 (interferon, beta 2) & 34 \\
\hline IL8 & Interleukin 8 & 336 \\
\hline IRAK2 & Interleukin-1 receptor-associated kinase 2 & 11 \\
\hline JUN & Jun oncogene & 10 \\
\hline LTA & Lymphotoxin alpha (TNF superfamily, member 1) & 5 \\
\hline NFKB2 & Nuclear factor of kappa light polypeptide gene enhancer in B-cells 2 (p49/p100) & 8 \\
\hline NFKBIA & Nuclear factor of kappa light polypeptide gene enhancer in B-cells inhibitor, alpha & 6 \\
\hline REL & V-rel reticuloendotheliosis viral oncogene homolog & 4 \\
\hline RELA & V-rel reticuloendotheliosis viral oncogene homolog A, & 2 \\
\hline RIPK2 & Receptor-interacting serine-threonine kinase 2 & 4 \\
\hline TLR2 & Toll-like receptor 2 & 3 \\
\hline TNF & Tumor necrosis factor (TNF superfamily, member 2) & 53 \\
\hline TICAM1 & Toll-like receptor adaptor molecule 1 & 3 \\
\hline
\end{tabular}

Semiconfluent RWPE-1 monocell-layers were infected with $P$. acnes at a MOI of 16:1. After $24 \mathrm{~h}$ infection, the cells were harvested, mRNA was collected and cDNA was prepared. The cDNA corresponding to 84 inflammation-associated genes was quantified with qRT-PCR and compared with cDNA prepared from non-infected cells. Inclusion criteria: $>2$-fold up-regulation, $(p=0.05)$.

longed treatment with IL-6, prostate cancer cells can alter the responsiveness to the cytokine and acquire the ability to proliferate at a higher rate and become more tumorigenic [33,34]. IL-8 has been shown to increase the transcriptional activity of the androgen receptor in prostate cancer cell lines, suggesting a potential role of this chemokine in modulating the transition of prostate cancer to an androgen-independent state [35]. Other studies report that IL-8 contribution to prostate cell proliferation is independent of the androgen receptor [36]. Our data indicate that the prostate epithelium significantly contributes to locally increased levels of both IL-6 and IL-8 when infected with $P$. acnes, thus potentially promoting adverse effects as increased proliferation and angiogenic activities by autocrine and/or endocrine mechanisms. The pathogenesis of $P$. acnes in locations other than the hair-follicle is still poorly understood. We currently address questions about its involvement in prostate disease such as prevalence, genetic variability and impact on histological inflammation and neoplasia (Elgh et al., manuscripts in preparation).

\section{Conclusions}

In conclusion, we demonstrate that prostate epithelial cells secrete inflammatory cytokines in response to $P$. acnes, partly through a TLR2-mediated mechanism. We propose that this strong immune-stimulating effect facilitates the bacterial colonization deeper into the prostate tissue where P. acnes can form long-lasting biofilm-like aggregates [7]. A possible mechanism may involve intracellular transport in recruited macrophages, as P. acnes has been demonstrated to withstand degradation by phagocytosing mononuclear cells [37].

\section{Methods}

\section{Prostate cell lines}

RWPE-1, human prostate epithelial cell line (ATCC ${ }^{\odot}$ CRL-11609) was maintained in complete KSF-medium supplemented with $5 \mathrm{ng} / \mathrm{l} \mathrm{EGF,} 0.05 \mathrm{mg} / \mathrm{l} \mathrm{BPE}$ and $100 \mathrm{U} /$ ml PEST (GIBCO BRL/Life technologies, Inc., Gaithersburg, MD, USA).

Cells were split 1:5, 1-2 times per week using 0,05\% (w/ v) trypsin/EDTA (GIBCO BRL/Life technologies, Inc., Gaithersburg, MD, USA). Cells were maintained in a humidified incubator at $37 \mathrm{C}$ containing $5 \% \mathrm{CO}_{2}$.

\section{Propionibacterium acnes}

$P$. acnes, serotype 1a, isolated from craniopharyngeom fluid was grown in Brain-Heart Infusion Broth $+5 \%$ horse serum at $37 \mathrm{C}$ under microaerobic conditions. The 
Table 2: List of genes that are downregulated upon P. acnes infection.

\begin{tabular}{llc}
\hline Gene name & Description & Fold upregulation \\
\hline FOS & V-fos FBJ murine osteosarcoma viral oncogene homolog & -3 \\
HMGB1 & High-mobility group box 1 & -3 \\
TLR4 & Toll-like receptor 4 & -4 \\
UBE2V1 & Ubiquitin-conjugating enzyme E2 variant 1 & -3 \\
\hline
\end{tabular}

Semiconfluent RWPE-1 monocell-layers were infected with $P$. acnes at a MOI of 16:1. After $24 \mathrm{~h}$ infection, the cells were harvested, mRNA was collected and CDNA was prepared. The CDNA corresponding to 84 inflammation-associated genes was quantified with qRT-PCR and compared with cDNA prepared from non-infected cells. Inclusion criteria: $>2$-fold down-regulation, $(p=0.05)$.

bacteria were grown to a density of $10^{9}$ per ml, pelleted and resuspended into sterile PBS.

\section{Cytokine ELISA}

RWPE-1 cells were seeded into 24-well plates at a density of $1 \times 10^{5}$ cells per well in one ml normal growth medium. After $48 \mathrm{~h}$, cells were washed in PBS and the medium was changed to DMEM without FCS and PEST. Cells were infected with $P$. acnes at a MOI of 16:1 and immediate close contact between bacteria and cells was achieved by centrifugation of the flask for $10 \mathrm{~min}$ at $700 \mathrm{~g}$. Noninfected cells were used as controls.

For the TLR2 blocking experiments, RWPE-1 cells were pre-treated with mouse anti-mouse/human TLR2 mAb (clone T2.5 [13] cat.code: mab-mtrl2, InVivoGen, San Diego, USA) at the concentration $100 \mathrm{ng} / \mathrm{ml}$ for $1 \mathrm{~h}$. The cells were then infected with $P$. acnes as described above.

Supernatants were harvested after $24 \mathrm{~h}$ and $48 \mathrm{~h}$. Supernatants were cleared from particles by centrifugation $10 \mathrm{~min}$ at $12000 \mathrm{~g}$, stored at $-20 \mathrm{C}$ and later assayed for IL-6, IL-8 and GM-CSF by ELISA (R\&D systems, Minneapolis, Minnesota) according to manufacturer's instruction.

\section{RNA preparation and Reverse Transcription PCR}

Cells were seeded at a density of $1 \times 10^{6}$ in a $25 \mathrm{~cm}^{2} \mathrm{cul}-$ ture flask in normal growth medium. After $48 \mathrm{~h}$, cells were washed in PBS and the medium were changed to DMEM without FCS and PEST. Cells were infected with P. acnes at a MOI of 16:1 and immediate close contact between bacteria and cells were achieved by centrifugation of the flask for $10 \mathrm{~min}$ at $700 \mathrm{~g}$. Total RNA was prepared after $0 \mathrm{~h}$ and $24 \mathrm{~h}$ using RNeasy Mini kit (Qiagen, Hilden, Germany) with the on-column DNase treatment step according to manufacturer's instruction. Cells were trypsinised using 0,05\% (w/v) trypsin/EDTA, lysed in 350 $\mu \mathrm{l}$ RTL buffer and homogenized in a TissueLyser with Stainless steel Beads, $5 \mathrm{~mm}$ (Qiagen, Hilden, Germany).

RNA concentration and purity were assessed in a NanoDrop $^{\oplus}$ ND-1000 spectrophotometer (Thermo scientific,
Wilmington, USA) at A260 and the ratios of A260:A230 and A260:280.

Complementary DNA (cDNA) was generated from one $\mu \mathrm{g}$ total RNA using RT2 First strand kit (SABiosciences, Frederick, MD, USA) according to the manufacturer's instruction. Quality of the cDNA was verified by PCR array housekeeping genes: beta-2-microglobulin, hypoxanthine phosphoribosyltransferase 1 , ribosomal protein L13a, glyceraldehyde-3-phosphate dehydrogenase, betaactin using primers from (SABiosciences, Frederick, MD, USA).

\section{Real-time Quantitative PCR}

Gene expression analysis measuring transcription of 84 inflammation associated genes was conducted using the RT $^{2}$ Profiler PCR Array, Human Toll-Like Receptor Signaling Pathway PAHS-018A (SABiosciences, Frederick, MD, USA) according to manufacturer's instruction. Realtime PCR detection was performed with an $\mathrm{IQ}^{\mathrm{m}} 5$ instrument (Bio-Rad, Hercules, CA, USA).

Complete list of genes analyzed by the array can be found at: http://www.SABiosciences.com

\section{Data Analysis}

Relative gene expression was calculated with the $\Delta \Delta \mathrm{C}_{\mathrm{t}}$ method in the web-based software package for $\mathrm{RT}^{2}$ Profiler PCR array systems (SABiosciences, Frederick, MD, USA).

\section{Statistical Methods}

Due to the small sample size $(n=3)$, a permutation test was used to test possible regulation [38]. A null hypothesis corresponding to no regulation was tested for each gene and each protein concentration and rejected for $p=$ 0.05 .

\section{Authors' contributions}

JBD carried out the tissue culture infections, the mRNA assays and the protein quantification. OA participated in the experimental design. PB performed the statistical analysis. FE initiated the study and participated in its design. $\mathrm{JO}$ participated in the design of the study, performed pilot studies of experimental conditions and drafted the manuscript. All authors read and approved the final manuscript. 


\section{Acknowledgements}

Grant sponsor: Kempestiftelserna (OA, FE, JO); Grant sponsor: Lions Cancer Research Foundation and Cancerforskningsfonden Norrland (JO). Grant sponsor: Percy Falks stiftelse för forskning beträffande prostatacancer och bröstcancer $(J O)$. We thank Dr. Anna Fahlgren for critical reading of the manuscript.

\section{Author Details}

1Department of Clinical Microbiology/Virology, Umeå University, SE-901 87 Umeå, Sweden and 2Department of Clinical Medicine, School of Health and Medical Sciences, Örebro University, SE-701 82 Örebro, Sweden

Received: 26 May 2009 Accepted: 26 April 2010

Published: 26 April 2010

\section{References}

1. De Marzo AM, Platz EA, Sutcliffe S, Xu J, Gronberg H, Drake CG, Nakai Y, Isaacs WB, Nelson WG: Inflammation in prostate carcinogenesis. Nat Rev Cancer 2007, 7(4):256-269

2. Sun J, Turner A, Xu J, Gronberg H, Isaacs W: Genetic variability in inflammation pathways and prostate cancer risk. Urol Oncol 2007, 25(3):250-259.

3. Krieger JN, Riley DE, Vesella RL, Miner DC, Ross SO, Lange PH: Bacterial dna sequences in prostate tissue from patients with prostate cancer and chronic prostatitis. J Urol 2000, 164(4):1221-1228.

4. Hochreiter WW, Duncan JL, Schaeffer AJ: Evaluation of the bacterial flora of the prostate using a $16 \mathrm{~S}$ rRNA gene based polymerase chain reaction. J Urol 2000, 163(1):127-130.

5. Sfanos KS, Sauvageot J, Fedor HL, Dick JD, De Marzo AM, Isaacs WB: A molecular analysis of prokaryotic and viral DNA sequences in prostate tissue from patients with prostate cancer indicates the presence of multiple and diverse microorganisms. Prostate 2008, 68(3):306-320.

6. Alexeyev O, Olsson J, Elgh F: Is there evidence for a role of Propionibacterium acnes in prostatic disease? Urology 2009, 73(2):220-224.

7. Alexeyev OA, Marklund I, Shannon B, Golovleva I, Olsson J, Andersson C, Eriksson I, Cohen R, Elgh F: Direct visualization of Propionibacterium acnes in prostate tissue by multicolor fluorescent in situ hybridization assay. J Clin Microbiol 2007, 45(11):3721-3728.

8. Alexeyev O, Bergh J, Marklund I, Thellenberg-Karlsson C, Wiklund F, Gronberg H, Bergh A, Elgh F: Association between the presence of bacterial 16S RNA in prostate specimens taken during transurethral resection of prostate and subsequent risk of prostate cancer (Sweden). Cancer Causes Control 2006, 17(9):1127-1133.

9. Cohen RJ, Shannon BA, McNeal JE, Shannon T, Garrett KL: Propionibacterium acnes associated with inflammation in radical prostatectomy specimens: a possible link to cancer evolution? J Urol 2005, 173(6):1969-1974

10. Kim J: Review of the innate immune response in acne vulgaris: activation of Toll-like receptor 2 in acne triggers inflammatory cytokine responses. Dermatology 2005, 211(3):193-198.

11. Vowels BR, Yang S, Leyden JJ: Induction of proinflammatory cytokines by a soluble factor of Propionibacterium acnes: implications for chronic inflammatory acne. Infect Immun 1995, 63(8):3158-3165.

12. Cumming G, Fidler F, Vaux DL: Error bars in experimental biology. J Cell Biol 2007, 177(1):7-11.

13. Meng G, Rutz M, Schiemann M, Metzger J, Grabiec A, Schwandner R Luppa PB, Ebel F, Busch DH, Bauer S, et al:: Antagonistic antibody prevents toll-like receptor 2-driven lethal shock-like syndromes. $J$ Clin Invest 2004, 113(10):1473-1481.

14. Maitland NJ, Collins AT: Inflammation as the primary aetiological agent of human prostate cancer: a stem cell connection? J Cell Biochem 2008, 105(4):931-939.

15. Haverkamp J, Charbonneau B, Ratliff TL: Prostate inflammation and its potential impact on prostate cancer: a current review. J Cell Biochem 2008, 103(5):1344-1353.

16. Sutcliffe S, Platz EA: Inflammation in the etiology of prostate cancer: an epidemiologic perspective. Urol Oncol 2007, 25(3):242-249.

17. De Marzo AM, Nakai Y, Nelson WG: Inflammation, atrophy, and prostate carcinogenesis. Urol Oncol 2007, 25(5):398-400.
18. Al-Mously N, Eley A: Interaction of Chlamydia trachomatis serovar E with male genital tract epithelium results in secretion of proinflammatory cytokines. J Med Microbio/ 2007, 56(Pt 8):1025-1032.

19. Takeyama K, Mitsuzawa H, Shimizu T, Konishi M, Nishitani C, Sano H, Kunishima Y, Matsukawa M, Takahashi S, Shibata K, et al:: Prostate cell lines secrete IL-8 in response to Mycoplasma hominis through Toll-like receptor 2-mediated mechanism. Prostate 2006, 66(4):386-391.

20. Jugeau S, Tenaud I, Knol AC, Jarrousse V, Quereux G, Khammari A, Dreno B: Induction of toll-like receptors by Propionibacterium acnes. $\mathrm{Br} J$ Dermatol 2005, 153(6):1105-1113.

21. Kundu SD, Lee C, Billips BK, Habermacher GM, Zhang Q, Liu V, Wong LY, Klumpp DJ, Thumbikat P: The toll-like receptor pathway: a novel mechanism of infection-induced carcinogenesis of prostate epithelial cells. Prostate 2008, 68(2):223-229.

22. Gatti G, Rivero V, Motrich RD, Maccioni M: Prostate epithelial cells can act as early sensors of infection by up-regulating TLR4 expression and proinflammatory mediators upon LPS stimulation. J Leukoc Biol 2006, 79(5):989-998.

23. Takeda K, Kaisho T, Akira S: Toll-like receptors. Annu Rev Immunol 2003, 21:335-376.

24. Chen Q, Koga T, Uchi H, Hara H, Terao H, Moroi Y, Urabe K, Furue M: Propionibacterium acnes-induced IL-8 production may be mediated by NF-kappaB activation in human monocytes. J Dermatol Sci 2002, 29(2):97-103.

25. Kishimoto T: Interleukin-6: from basic science to medicine--40 years in immunology. Annu Rev Immunol 2005, 23:1-21.

26. Waugh DJ, Wilson C: The interleukin-8 pathway in cancer. Clin Cancer Res 2008, 14(21):6735-6741

27. Hamilton JA: GM-CSF in inflammation and autoimmunity. Trends Immunol 2002, 23(8):403-408.

28. Gillitzer R, Berger R, Mielke V, Muller C, Wolff K, Stingl G: Upper keratinocytes of psoriatic skin lesions express high levels of NAP-1/IL-8 mRNA in situ. J Invest Dermatol 1991, 97(1):73-79.

29. Abd El All HS, Shoukry NS, El Maged RA, Ayada MM: Immunohistochemical expression of interleukin 8 in skin biopsies from patients with inflammatory acne vulgaris. Diagn Pathol 2007, 2:4.

30. Hobisch A, Rogatsch H, Hittmair A, Fuchs D, Bartsch G Jr, Klocker H, Bartsch G, Culig Z: Immunohistochemical localization of interleukin-6 and its receptor in benign, premalignant and malignant prostate tissue. J Patho/ 2000, 191(3):239-244

31. Giri D, Ozen M, Ittmann M: Interleukin-6 is an autocrine growth factor in human prostate cancer. Am J Pathol 2001, 159(6):2159-2165.

32. Culig Z, Steiner H, Bartsch G, Hobisch A: Interleukin- 6 regulation of prostate cancer cell growth. J Cell Biochem 2005, 95(3):497-505.

33. Hobisch A, Ramoner R, Fuchs D, Godoy-Tundidor S, Bartsch G, Klocker H, Culig Z: Prostate cancer cells (LNCaP) generated after long-term interleukin 6 (IL-6) treatment express IL-6 and acquire an IL-6 partially resistant phenotype. Clin Cancer Res 2001, 7(9):2941-2948.

34. Steiner H, Godoy-Tundidor S, Rogatsch H, Berger AP, Fuchs D, Comuzzi B, Bartsch G, Hobisch A, Culig Z: Accelerated in vivo growth of prostate tumors that up-regulate interleukin- 6 is associated with reduced retinoblastoma protein expression and activation of the mitogenactivated protein kinase pathway. Am J Pathol 2003, 162(2):655-663.

35. Seaton A, Scullin P, Maxwell PJ, Wilson C, Pettigrew J, Gallagher R, O'Sullivan JM, Johnston PG, Waugh DJ: Interleukin-8 signaling promotes androgen-independent proliferation of prostate cancer cells via induction of androgen receptor expression and activation. Carcinogenesis 2008, 29(6):1148-1156.

36. Araki S, Omori Y, Lyn D, Singh RK, Meinbach DM, Sandman Y, Lokeshwar VB, Lokeshwar BL: Interleukin-8 Is a Molecular Determinant of Androgen Independence and Progression in Prostate Cancer. Cancer Res 2007, 67(14):6854-6862.

37. Webster GF, Leyden JJ, Musson RA, Douglas SD: Susceptibility of Propionibacterium acnes to killing and degradation by human neutrophils and monocytes in vitro. Infect Immun 1985, 49(1):116-121.

38. Good Pl: Permutation tests: a practical guide to resampling methods for testing hypotheses. 2nd edition. New York: Springer; 2000.

doi: 10.1186/1471-2180-10-126

Cite this article as: Drott et al., Propionibacterium acnes infection induces upregulation of inflammatory genes and cytokine secretion in prostate epithelial cells BMC Microbiology 2010, 10:126 